\title{
Ethics Audit \\ Of A Therapeutic Recreation Course
}

Nancy Nisbett, (Email: nancyni@csufresno.edu), California State University, Fresno Jennifer Hinton, (Email: hinton@ohio.edu), Ohio University

\begin{abstract}
The purpose of this study was to enhance awareness of the presence of ethics education within the allied health discipline of therapeutic recreation. To achieve this end, a curriculum audit was conducted in a therapeutic recreation course to determine the existence of ethics education within the course. Included topics, methods of delivery, and degree of student-initiation were all considered. Findings suggest the frequent presence of ethics content; however, an explicit connection between the course content and ethics was not always made. Discussion was found to be the main delivery method. Recommendations are discussed.
\end{abstract}

\section{INTRODUCTION}

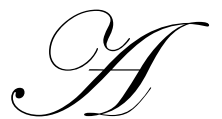

goal in the education of healthcare professionals is the development of ethical practitioners. ${ }^{1}$ In therapeutic recreation (TR) professional preparation, however, how students obtain ethics knowledge has not been comprehensively addressed. ${ }^{2}$ Sylvester, ${ }^{3(\mathrm{p} 331)}$ arguing for an increased focus on ethics education stated, "Professional education ... must devote far more attention to the theory and practice of ethics." What content should be addressed and how to infuse this content within the curriculum are two existing issues. A curricular audit would be needed to obtain a clear picture of the extent of ethics education within TR curriculum. ${ }^{2}$

The intent of this study was to complete a curricular audit of one TR course to examine ethics education within that course. Three specific areas were examined. First, what ethics education topics are included within a TR course? Second, what methods are used to deliver ethics education within a TR course? Finally, to what extent are student-initiated questions responsible for the inclusion of ethics education within a TR course?

\section{BACKGROUND}

\section{Content Of Ethics Education}

Strike and Ternasky ${ }^{4}$ described professional ethics as the norms, values and principles that govern professional conduct. The authors concluded that higher societal expectations are placed on a person in his or her professional capacity, requiring that he or she be held to a higher level of conduct. They do not, however, address how a professional should be educated in order to meet this expectation.

A lack of standardization of ethics content is found throughout the allied health literature. After reviewing hundreds of articles, Layman ${ }^{5}$ found no consensus on ethics education content. Though devoid of standards, literature supports the concept that by providing a thorough understanding of ethical standards and practice in ethical decision-making, students will have an increased ability to comply with the ethical guidelines of their chosen profession. ${ }^{6,7}$

Within TR literature, one study identified common ethics education topics to include ethical problem solving, code of ethics, ethical principles, decision-making skills, professional versus personal convictions, identification of ethical dilemmas, and cultural differences. ${ }^{2}$ No consistency was found in the priority given to specific topics. 


\section{Teaching Methods For Ethics Education}

A discussion of appropriate teaching methods for content delivery continues throughout the allied health community. In addition to satisfying chosen learning objectives, selected teaching methods should foster interaction, stimulate thinking, encourage personal awareness, and challenge students to be open to different ethical viewpoints. Donovan et $\mathrm{al}^{8}$ advocated for experiential methods for learning, stating that the ability to learn facts and skills is enhanced when connected to problem-solving activities. While Woods ${ }^{9}$ found lectures, games, debates, case studies, and narratives common in nursing curricula, Holland ${ }^{10}$ found no consensus in the nursing literature on the best methods to teach ethics education. A survey of physical therapy programs found case studies, discussion, lecture, and activities to be the preferred methods, while a study involving general health care professionals found lectures and small group discussions to be most beneficial. ${ }^{11,12}$ Additional allied health literature also suggest the need to utilize approaches such as case studies and videos to augment clinical experience. ${ }^{10,13-15}$ Within recreation, Henderson and Bedini ${ }^{16}$ recommended using experiential education, stating ethical development is context dependent and requires practice. They advocated for the use of community service, analyzed in the classroom, to combine experience with learning. Within TR, lecture, discussion, and readings were found to be the agreed upon methods for instruction of ethics education. ${ }^{2}$

One teaching method rarely addressed is the use of student-initiated questions. Osborne and Martin ${ }^{17}$ suggested using students' previous experiences, but did not directly address students initiating the questions. The process of student-generated questions leading to awareness of ethical concepts, however, is supported by Andre, ${ }^{18}$ who stated that questioning and contemplation of ethical dilemmas helps to develop moral appreciation and judgment. This may be especially salient considering recent research suggesting that current methods of teaching ethical reasoning do not create more ethically competent professionals. ${ }^{10}$

\section{METHODS}

To obtain an accurate picture of ethics education in one TR course, a curricular audit was conducted. A curriculum audit is a process used to compare curriculum elements to existing standards. ${ }^{19}$ Required conditions to conduct a curricular audit include the existence of standards, the existence of data trails and records, the presence of valid and reliable procedures, the condition of independence, and the presence of objectivity. ${ }^{20}$

The present study met each condition listed above. The first condition, the existence of standards, was met in the form of literature identifying topics and methods that should be used to deliver ethics education. Secondly, data trails were present in the form of transcripts of classes, and all written material from the course. To satisfy the third condition, procedures were determined to be both valid and reliable through the use of literature to support the research design. In addition, expert analysis of research design was sought and the same procedures were used throughout the study to ensure consistency. The last two conditions, independence and objectivity were the most difficult to meet. The investigator observed the course in a non-participant role. However, as a faculty member in the same program at the university, the investigator's relationship with the instructor and students could have been seen to interfere with both of these conditions. In order to ensure both independence and objectivity, detailed audit trails were maintained and a journal was kept by the investigator to assist in the identification of potential observer bias during data collection and analysis. To reduce potential for bias, the investigator and the instructor refrained from any discussion of the course and the study.

\section{Description Of The Audited Course And Instructor}

A 4-credit course, titled Assessment and Documentation in Therapeutic Recreation, was selected. This course was the fourth in a series of six TR courses at this university. As this university used a quarter system, four credits indicate a 10-week, 40 hour course. This course was chosen due to appropriateness for inclusion of a nonparticipant observer and the assumed significance of professional ethics related to course topics.

The instructor was self-identified as comfortable with ethics, with ethics content included in graduate coursework and additional ethics workshops. As this is not necessarily characteristic, it is an important factor to note in the results. 


\section{Implementation Of The Audit}

Three sources of data were used; an instructor interview, a review of all written course materials, and class observations. The instructor was interviewed to determine her plan for the inclusion of ethics. Answers provided by the instructor, as well as content of the written materials, were compared with class observations for analysis. Interview questions included:

- $\quad$ How do you plan to include professional ethics within the course content?

- How many class periods do you plan to devote to this topic, how much time?

- What topics do you consider to be included within ethics education?

- Which of those topics do you consider relevant to the content of this course?

- How much prior exposure to professional ethics do you estimate students have?

- What is the extent of your training with professional ethics?

- How would you rate the importance of professional ethics education, why?

- What methods do you use to include professional ethics education within this course?

- To what extent do students initiate discussion of professional ethics in this course?

The investigator attended class as a non-participant observer to document instances of ethics education in planned lecture, discussion, and class exercises as well as student-initiated class discussions. Classes were audio taped to ensure accuracy of commentary for the investigator. Tapes were transcribed and coded for analysis. The impact of the non-participant observer within the course and the potential of this person and the audio recorder to affect choices made by the instructor or students must also be noted in the outcomes of this study.

\section{RESULTS}

Thirty-two of a potential 37 class sessions were observed and used for analysis. At the conclusion of the quarter, transcripts, interview data, and course materials were reviewed, unitizing the data by identifying units of meaning through examination of materials and labeling each unit. Once unitizing was done, comparison began. Findings were compared to the allied health literature to determine the extent of ethics education within this course.

\section{Type Of Ethics Education Content In The Course}

The course was evaluated using the topics identified in the allied health literature. In reviewing the transcripts, the investigator looked for content involving the following: ethical and bioethical issues, ethical principles, convictions, ethical theories, problem solving, codes of ethics, decision-making skills, professional versus personal convictions, identification of ethical dilemmas, and cultural differences. The instructor anticipated including decision-making skills, ethical issues, ethical principles, professional versus personal convictions, identification of ethical dilemmas, and cultural differences. A review of the syllabus and other course materials found the following topics to be readily apparent: decision-making skills (i.e. how to interpret assessment), ethical principles (i.e. role of external/internal regulations on client treatment), and cultural differences (i.e. how assessment results are affected by diversity).

Of the 32 classes, ethics content was included in 28. In some classes ethics content was mentioned once in passing; in others, a large part of a class period was devoted to one or more ethics education topics. In many instances, a connection was not made between the topic of discussion and ethics. For instance, in an instructor-led discussion of the client as a member of the treatment team, the point was made that a TR specialist needs to communicate assessment results with the client and solicit input. However, it was not directly stated to students that this is an ethical obligation of our profession, leaving the student to make this connection. The literature, however, has questioned students' ability to understand the pervasiveness of ethics unless it is continuously highlighted by the instructor and experienced by the student. ${ }^{21}$

Ethical principles were the most frequently discussed ethics education topic, with autonomy, justice, fidelity, informed consent, confidentiality and compliance with laws and regulations all receiving attention. 
Decision-making skills, ethical issues and cultural differences were also topics noted to have been presented by the instructor. Additionally, professional versus personal convictions and identification of ethical dilemmas were noted as student-generated topics. All topics were consistent with those reported in the TR literature and are less comprehensive than those reported in other allied health fields. ${ }^{2,5,12}$

\section{Ethics Education Content Teaching Methods Used By The Instructor}

A conversational teaching style best describes this instructor's approach; with discussion and exercise the most used methods. Throughout the quarter, however, numerous teaching methods were used. Those methods included: discussion, lecture, pair and small group exercises, consumer interaction, role play, reading, video, computer work, and guest speakers. Teaching aides included handouts, overheads, PowerPoint, and computer software. Assessment of learning was conducted through homework, quizzes, two major assignments, and a final exam, with student knowledge of ethics assessed through the two major assignments and the final.

Overwhelmingly, the ethics content in this course was delivered through discussion, consistent with the instructor's expectations. Lecture, exercises, reading and role play were also used to deliver ethics content to a much smaller extent. In most cases, these methods were used to identify an ethical issue which was then investigated through class discussion. For example, an in-class exercise involved the use of a computer program to practice assessment skills. After reviewing the exercise, the students learned their first task would be to choose the questions they wanted to ask their "client." After allowing the students to work with the questions for a while, the instructor queried, "Why are you choosing these questions and what are you going to do with the information?" That question led to a discussion of what types of questions TR specialists have the right to ask and how the information can be used. In another instance, a lecture by a guest speaker led to a discussion on autonomy. The speaker, a former rehabilitation client, presented the students with two therapist examples from the two facilities he stayed in during rehabilitation. In one instance, the therapist asked him what he wanted to do, in the other the therapist told him what to do. The follow up to this lecture provided an opportunity to introduce the subtle differences between encouraging and forcing clients.

As anticipated by the instructor, assignments were also helpful in stimulating discussion about ethics. As students prepared to complete a leisure assessment with consumers at a local sheltered workshop, students questioned how the assignment set up would impact confidentiality. A discussion of the meaning of confidentiality and best practices to ensure confidentiality in this particular environment followed.

The use of all five delivery methods mentioned above is consistent with the literature. Favored methods found by Layman ${ }^{5}$ (small-group teaching, moral dilemma discussion, and Socratic questioning) match the discussion style used by the instructor. As Henderson and Bedini ${ }^{16}$ suggest, the use of experiential techniques to learn assessment procedures (use of the computer program and assessing consumers at a sheltered workshop) also provided rich material for classroom discussion of the ethical implications of assessment and client interaction.

\section{Student-Initiated Questions}

The instructor predicted half of the ethical content delivered in this course would be student-initiated. This prediction related to the belief that ethical issues were one of the areas students were most interested in discussing. It was anticipated that in many cases the students would recognize something was wrong but may not understand it was an ethical issue.

Analysis revealed 16 instances of student-initiated questions related to ethics. While not equaling half of the ethical content, these questions did account for approximately $1 / 3$ of the ethics content in this course. "How do you obtain informed consent?" and "How do we decide who to include in treatment?" are examples of studentinitiated questions. In one instance, a guest speaker was lecturing on the use of the Functional Independence Measure (FIM Scale). One of the problems identified by the speaker in using this measure was the difficulty, at her facility, in agreeing on scoring. A student questioned if the speaker saw any ethical problems with using this scale. The speaker shared concerns about co-workers using the scale without proper training (competence) and an internal understanding that there had to be improvement in score from the initial assessment to the first week (fidelity). 


\section{DISCUSSION}

Ethics topics covered and teaching methods were not as varied in this course as topics and methods reported in allied health literature; however this snapshot is limited to that of one course. To get a full picture, all courses and field experiences would need to be audited. The topics and methods used, however, were consistent with findings in the TR literature. Although no pre test was done to determine the prior ethical awareness of students, the use of exercises and other experiential methods appears to have opened the door to enhanced discussion of ethical content and is worthy of further study to determine the effectiveness of these methods. Based on the observations from this course, educators should recognize the need to continuously reinforce the ethical content in these discussions to ensure students make the connection.

While Greene ${ }^{6}$ indicated that depending on students and their experiences for content may be unreliable, the amount of ethics content generated by student questions suggests this area deserves further consideration. As each student will bring different knowledge and experiences, the challenge for the educator will be to facilitate students' utilization of their own resources as well as moving the student from asking a question, to recognizing it is a question about ethics.

As is common in qualitative research, findings of this study suggest future studies. An audit of the entire TR curriculum at a university is in order to follow-up on this one-course snap-shot. It would be of interest to replicate this study with a similar course at another university for comparison. The perceived inability of the students to connect course content to ethics also suggests a need to further study students' understanding of ethics. Lastly, there is little reference in the literature for methods to assess the ethical development of students, and studies which do exist are marred by inaccuracies. ${ }^{22}$ As stated by Sylvester, ${ }^{3}$ the profession needs to determine how to prepare and measure the moral character of its future professionals.

In addition to the suggestions for educators given above, the most practical finding from this study is applicable to educators and internship/fieldwork supervisors alike. It is our duty to reinforce connections between course topics/field situations and ethics frequently. We cannot assume that just because a student is exposed to a situation involving an ethical dilemma, whether in class or in the field, that they will recognize it as such and be able to determine the appropriate action. It is the task of the educator/supervisor to overtly guide the student to this awareness. If one agrees with Kohlberg's ${ }^{23}$ depiction of the path of moral reasoning, it is incumbent upon all of us, from student through seasoned professional to continuously expose ourselves to opportunities to better develop our recognition and understanding of ethics.

\section{REFERENCES}

1. Hattab AS. Current trends in teaching ethics of healthcare practices. Developing World Bioethics. 2004;4(2):160-172.

2. Nisbett N, Brown-Welty S, O'Keefe C. A study of ethics education within therapeutic recreation curriculum. Ther Recreation J. 2002;36(3):282-295.

3. Sylvester CD. Ethics and quest for professionalization. Ther Recreation J. 2002;36(4):314-334.

4. Strike KA, Ternasky PL. Introduction: ethics in educational settings. In Strike KA, Ternasky PL, eds. Ethics for Professionals in Education: Perspectives for Preparation and Practice. New York, NY: Teachers College Press; 1993:1-9.

5. Layman E. Ethics education: curricular considerations for the allied health disciplines. J Allied Health. 1996;29(2):149-160.

6. Greene D. The use of service learning in client environments to enhance ethical reasoning in students. Am $J$ Occup Ther. 1997;51(10):844-852.

7. Shank PA. Doing ethics: toward the resolution of ethical dilemmas. In: Sylvester C. ed. Philosophy of Therapeutic Recreation: Ideas and Issues Volume II. Ashburn, VA: National Therapeutic Recreation Society; 1996:30-56.

8. Donovan MS, Bransford JD, Pellegrino JW, eds. How People Learn: Bridging Research and Practice. Washington, DC: National Academy Press; 1999. 
9. Woods M. Nursing ethics education: are we really delivering the good(s)? Nurs Ethics. 2005;12(1):5-18.

10. Holland S. Teaching nursing ethics by cases: a personal perspective. Nurs Ethics. 1999;6(5):434-436.

11. Malek JI, Gellar G, Sugarman J. Talking about cases in bioethics: the effect of an intensive course on health care professionals. J Med Ethics. 2000;26(2):131-136.

12. Triezenberg HL. Teaching ethics in physical therapy education: a delphi study. J Phys Ther Ed. 1997;11(2):16-22.

13. Stone JA, Haas BA, Harmer-Beem MJ, Baker DL. Utilization of research methodology in designing and developing an interdisciplinary course in ethics. J Interprofessional Care. 2004;18(1):57-62.

14. Dodd SJ, Jansson B. Expanding the boundaries of ethics education: preparing social workers for ethical advocacy in an organizational setting. J Soc Work Ed. 2004;40(3):455-465.

15. Graham C, Babola K. Needs assessment of non-traditional students in physical and occupational therapy programs. J Allied Health. 1998;27(4):196-201.

16. Henderson KA, Bedini LA. Teaching ethics and social responsibility in leisure studies curricula. Schole. 1990;29:1-13.

17. Osborne LW, Martin CM. The importance of listening to medical students' experiences when teaching them medical ethics. $J$ of Med Ethics. 1989;15(1):35-38.

18. Andre J. Beyond moral reasoning: a wider view of the professional ethics course. Teaching Philosophy. 1991;14:359-373.

19. Seager SR, Anema MG. A process for conducting a curriculum audit. Nurse Educator. 2003;28(1): 5-6.

20. English FW. Deciding What to Teach and Test: Developing, Aligning, and Auditing the Curriculum. millennium ed. Thousand Oaks, CA: Corwin Press, Inc; 2000.

21. Triezenberg HL, Davis CM. Beyond the code of ethics: educating physical therapists for their role as moral agents. J Phys Ther Ed. 2000;14(3):48-58.

22. Duckett L, Rowan-Boyer M, Ryden MB, Crisham P, Savik K, Rest JR. Challenging misperceptions about nurses' moral reasoning. Nurs Res. 1992;41(6):324-331.

23. Kohlberg L. Moral stages and moralization. In: Lickona T, ed. Moral Development and Behavior: Theory Research and Social Issues. New York, NY: Holt, Rinehart \& Winston; 1976:1005-1067. 